Available online at GSC Online Press Directory

GSC Biological and Pharmaceutical Sciences

e-ISSN: 2581-3250, CODEN (USA): GBPSC2

Journal homepage: https://www.gsconlinepress.com/journals/gscbps

(RESEARCH ARTICLE)

\title{
Development and formulation of Aloe vera emulgel
}

\author{
Mahuli Manna and Anandamoy Rudra * \\ Associate Professor, Bengal School of Technology, Sugandha, Delhi Road, Hooghly-712102, West Bengal, India.
}

Publication history: Received on 11 August 2020; revised on 20 August 2020; accepted on 21 August 2020

Article DOI: https://doi.org/10.30574/gscbps.2020.12.2.0262

\begin{abstract}
Aloe vera is most popular in treatment of dermatological disorder in case of burn, tan and wound healing. The study was designed for crude Aloe vera extract, development of oil in water (o/w) emulsion, preparation of gel base using Aloe vera extract and formulation of the emulgel for topical application. The formulation was prepared by using carbomer 940 as polymer and isopropyl alcohol as penetration enhancer. The $\mathrm{p}^{\mathrm{H}}$ and viscosity of the Aloe vera emulgel were noticed to be 6.8 and 750 centipoise (cps) respectively. The interaction study between phytochemicals and the excipients was carried out using Fourier transform infrared (FTIR) spectroscopy. UV spectrometric analysis of plant extract was carried out. Dynamic light scattering (DLS) was performed to determine the particle size distribution of oil globules in emulsion. Mean particle size (oil globules) was observed to be $481 \mathrm{~nm}$. Zeta potential and polydispersity index (PDI) was recorded to be $-13.2 \mathrm{mV}$ and 0.6 respectively.
\end{abstract}

Keywords: Aloe vera gel; Carbomer 940; Emulgel; Fourier transform infrared (FTIR) spectroscopy; Dynamic light scattering (DLS); Dermal preparation

\section{Introduction}

Topical delivery is an important route for local and systemic treatment. Topical delivery is defined as the application of a formulation containing drug to the skin to directly treat cutaneous disorders (eg. acne) is used both in cosmetic and pharmaceutical preparations. The delivery of drugs onto the skin is recognized as an effective therapy for local dermatologic diseases. It can penetrate deeper into skin and hence give better absorption [1]. Gels are a relatively newer class of dosage form created by entrapment of large amount of aqueous or hydro-alcoholic liquid in a network of colloidal solid particles. In spite of many advantages offered by gels a major limitation is in the delivery of hydrophobic drugs. So to overcome this drawback an emulgel based approach has been appreciated which is the combination of emulsion and gel. Emulgels for dermatological use have several favourable properties such as being thixotropic, greaseless, easily spreadable, easily removable, emollient, long shelf life, transparent [2]. Aloe vera has an ancient history in medicine, it is natively from Africa, but widely used in Iran, Egypt, Greece, Rome and India. Aloe barbadensis Miller belonging to family Liliaceae was found to grow in subtropical and tropical climates. Recently, only a few species of Aloe vera is most popular in treatment of dermatological disorders. Aloe vera leaves are formed by a thick epidermis covered with cuticle that can be differentiated into thinner walled cells forming parenchyma with large water storage tissue.

This cells containing a transparent mucilaginous jelly which is referred as Aloe vera gel. It contains 99-99.5\% water and the remaining $0.5-1.0 \%$ solid material is reported to contain over 75 different potentially active compounds including lignin, saponin, salicylic acid, sterols, triterpenoid, various vitamins, minerals, enzymes, polysaccharides, phenolic compounds and organic acids. Aloe vera gel has been used for a number of skin issues such as discoloration, pigmentation, tanned skin, rashes and sunburns, premature ageing, dry skin, pimples/acne and scars or any dark spots

\footnotetext{
* Corresponding author: Anandamoy Rudra

Bengal School of Technology, Sugandha, Delhi Road, Hooghly-712102, West Bengal, India
}

Copyright (C) 2020 Author(s) retain the copyright of this article. This article is published under the terms of the Creative Commons Attribution Liscense 4.0. 
on the skin [3]. Aloe vera gel promotes in vitro skin penetration of compounds. Some constituents of the Aloe vera gel itself also penetrate the skin and this was interestingly dependent on the molecular weight of the co-applied compounds. The higher the molecular weight of the co-applied compound, the less of the gel components were transported across the skin [4]. Aloe vera serves for numerous purposes is used both internally and externally for multiple functions. It is widely used for treating various digestive and dermatological disorders. It acts as immunomodulator and is used for skin care applications [5]. Crude Aloe vera gel accelerates burn wound healing. Mannose-6-phosphate as the active part of Aloe vera consists of linear chains of glucose and mannose molecules that promotes the proliferation and migration of fibroblasts and keratinocytes may play an important roles in wound healing [6].

The study was designed for crude Aloe vera extract, development of oil in water (o/w) emulsion, preparation of gel base using Aloe vera extract and formulation of the emulgel for topical application. The formulation was prepared by using carbomer 940 as polymer and isopropyl alcohol as penetration enhancer.

\section{Preparation of Aloe vera extract}

A few Aloe vera leaves from an Aloe barbadensis Miller plant were collected and washed with water thoroughly. A sharp knife was taken and carefully peeled off the yellow layer just beneath the green rind avoiding the vascular bundles and the top rind was removed. The bottom rind was similarly removed to discard the significant amount of mucilage which gets attached onto this. The clear mucilaginous gel was scooped out with a spoon. $50 \mathrm{ml}$ crude clear Aloe vera extract was mixed uniformly by using magnetic stirrer and the plant extract was filtered through a Whatman filter paper. Finally, it was transferred into a sterilized, clean glass jar and stored in the refrigerator [6].

\section{Formulation of Aloe veraemulgel}

The gel base was prepared by dispersing $1 \%$ carbomer 940 in distilled water at $80^{\circ} \mathrm{C}$ with constant stirring at a moderate speed using magnetic stirrer and $\mathrm{p}^{\mathrm{H}}$ was adjusted to 6-7 using triethanolamine (TEA). $50 \mathrm{ml}$ of Aloe vera extract was added into it and gel base using Aloe vera extract was prepared. The oil phase of the emulsion was prepared by dissolving $0.5 \mathrm{ml}$ span 20 in $7.5 \mathrm{ml}$ coconut oil. 1\% of zinc oxide was added into it. Zinc oxide protects skin from UVinduced damage. The aqueous phase was prepared by dissolving $1 \mathrm{ml}$ tween 20 in purified water. Required amount of methyl paraben was added into aqueous phase and propyl paraben was dissolved in oil phase. Two phases were separately heated to $70-80{ }^{\circ} \mathrm{C}$. The oil phase was added dropwise to aqueous phase and was mixed together with continuous stirring using mechanical stirrer at specified speed until it cooled down to room temperature. The prepared emulsion was mixed with the gel in 1:1 ratio with gentle stirring to obtain the Aloe vera emulgel [6].

\section{Characterization of formulation}

\subsection{Viscosity and $\mathrm{p}^{\mathrm{H}}$ of emulgel}

Viscosity of the prepared Aloe vera emulgel was determined using Brookfield viscometer (spindle type) at 10 rpm and was to be $750 \mathrm{cps}$ and $\mathrm{p}^{\mathrm{H}}$ of the formulated emulgel was determined to be 6.8[7].

\subsection{UV -visible spectroscopy of Aloe vera extract}

The plant extract was diluted with propylene glycol. Then the sample was analyzed by using UV visible spectrophotometer within the range of 200-500 nm.

\subsection{Drug excipients interaction study}

\subsubsection{Fourier transform infrared (FTIR) spectroscopy}

The pure carbomer 940, Aloe vera leaf extract and Aloe vera emulgel were mixed separately with IR grade KBr and corresponding pellets were prepared by applying specified pressure in a hydraulic press. The pellets were scanned over a wave number range of 4000 to $400 \mathrm{~cm}^{-1}$ in FTIR spectroscope [8].

\subsection{Size determination and zeta potential measurement}

Size distribution was measured using dynamic light scattering (DLS) technique. The size distribution of small particles (oil globules) in emulsion was determined. Zeta potential study was conducted following guidelines [8]. 


\subsection{Optical microscopy of emulsion}

The prepared o/w emulsion was observed under optical microscope at magnification of 60X.

\section{Results and discussion}

IR spectrum of Aloe vera extract consists of a single peak at $3327 \mathrm{~cm}^{-1}$ due to the presence of N-H stretching. Some peaks were observed at $2207 \mathrm{~cm}^{-1}, 2164 \mathrm{~cm}^{-1}$ and $2103 \mathrm{~cm}^{-1}$ were associated with $\mathrm{C} \equiv \mathrm{C}$ stretching. Absorption band at 1638 $\mathrm{cm}^{-1}$ was characteristic of $\mathrm{C}=0$ stretching that indicates the presence of carbonyl groups. The absorption band at 970 $1250 \mathrm{~cm}^{-1}$ corresponds to the stretching vibrations of C-O groups of esters and phenols. A single peak at $690 \mathrm{~cm}^{-1} \mathrm{was}$ recorded due to the presence of $\mathrm{C}-\mathrm{H}$ bending (Figure 1) [9].

In case of IR spectrum of carbomer 940, peaks were observed at $2970 \mathrm{~cm}^{-1}$ and $2661 \mathrm{~cm}^{-1}$ which were associated with alkane C-H stretching. Two peaks were observed at $2211 \mathrm{~cm}^{-1}$ and $2180 \mathrm{~cm}^{-1}$ due to alkyne $\mathrm{C} \equiv \mathrm{C}$ stretching. Another two peaks were observed at $1910 \mathrm{~cm}^{-1}$ and $1701 \mathrm{~cm}^{-1}$ were associated with alkene $\mathrm{C}=\mathrm{C}$ stretching and acid $\mathrm{C}=0$ stretching. Two peaks were observed at $1451 \mathrm{~cm}^{-1}, 1415 \mathrm{~cm}^{-1}$ due to the presence of aromatic $\mathrm{C}=\mathrm{C}$ stretching. Another peaks were observed at $1217 \mathrm{~cm}^{-1}, 1230 \mathrm{~cm}^{-1}$ and $1115 \mathrm{~cm}^{-1}$ were characteristic of alcohol C-0 stretching and at $892 \mathrm{~cm}^{-1}, 798 \mathrm{~cm}^{-1}$ and $672 \mathrm{~cm}^{-1}$ were associated with amine N-H bending (Figure 2)[11].

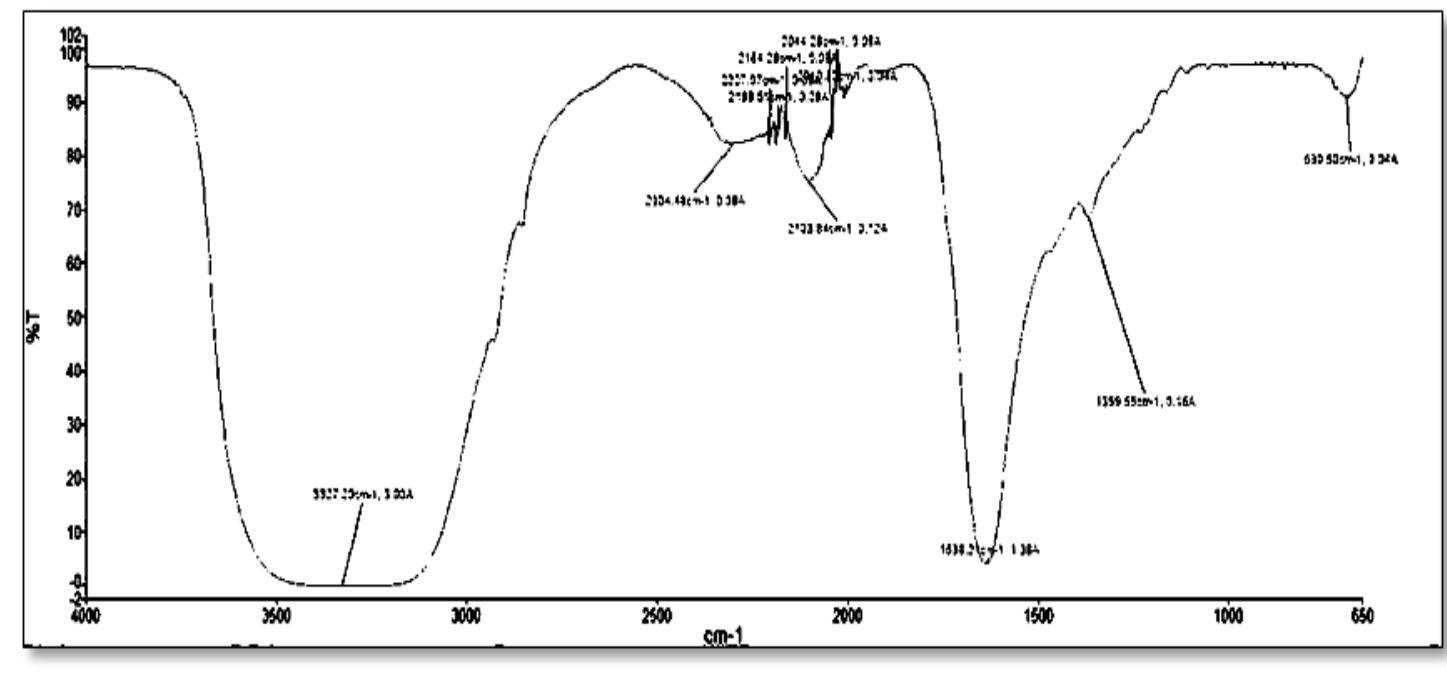

Figure 1 FTIR spectra of Aloe vera extract

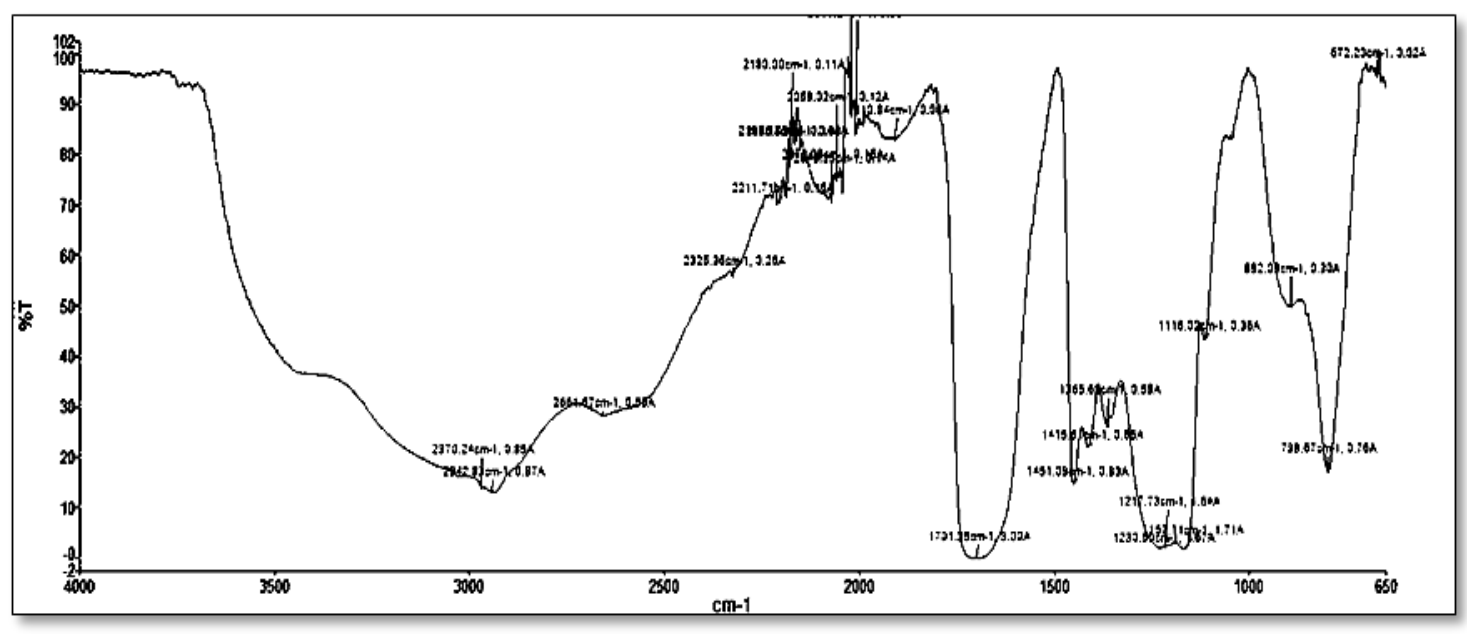

Figure 2 FTIR spectra of carbomer 940 


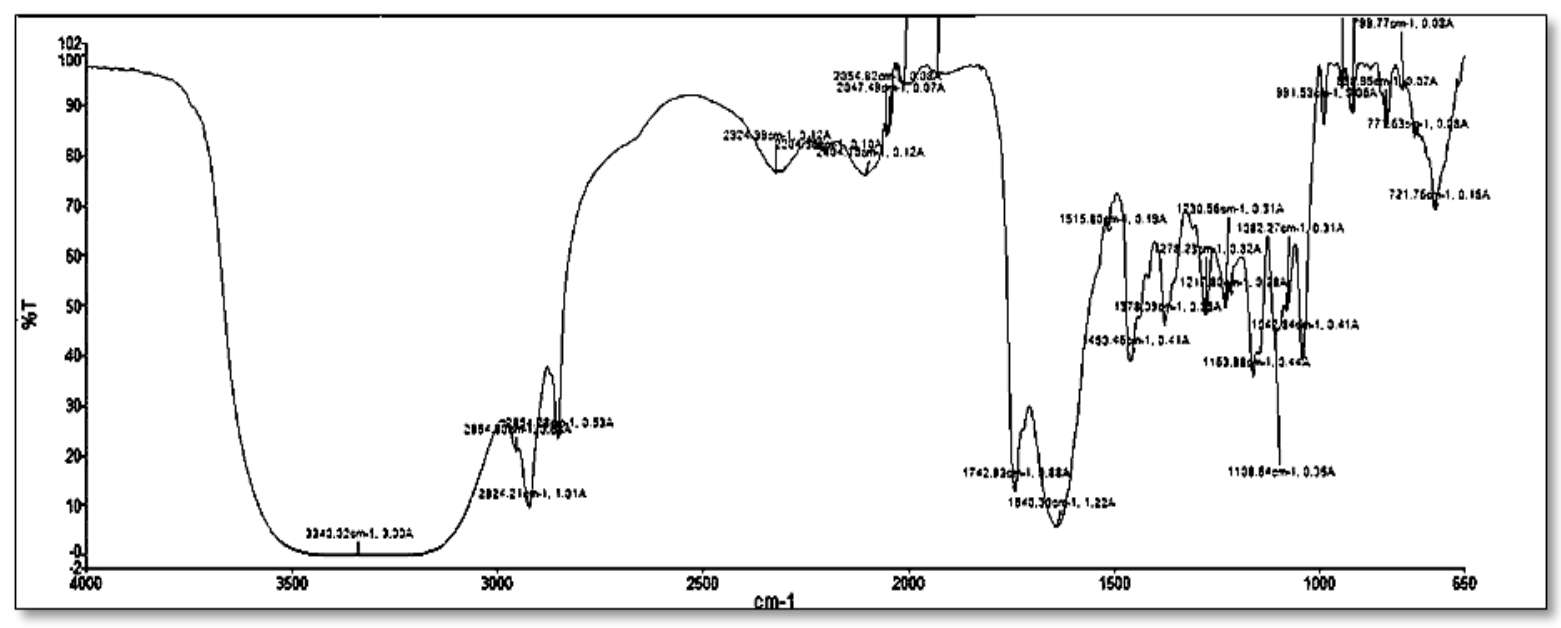

Figure 3 FTIR spectra of Aloe vera emulgel

IR spectrum of Aloe vera emulgel contains many peaks. Single Peak was recorded at $3340 \mathrm{~cm}^{-1}$ due to amine N-H stretching. Two peaks were at $2954 \mathrm{~cm}^{-1}$ and $2204 \mathrm{~cm}^{-1}$ due to alkane $\mathrm{CH}_{2}$ and $\mathrm{CH}_{3}$ stretching and alkyne $\mathrm{C} \equiv \mathrm{C}$ stretching. Another two were at $1742 \mathrm{~cm}^{-1}, 1640 \mathrm{~cm}^{-1}$ due to acid $\mathrm{C}=0$ stretching and alkene $\mathrm{C}=\mathrm{C}$ stretching. Some were at 1516 $\mathrm{cm}^{-1}, 1460 \mathrm{~cm}^{-1}, 1378 \mathrm{~cm}^{-1}$ due to amine N-H bending and alkane $\mathrm{CH}_{3}$ bending. Another were at $1278 \mathrm{~cm}^{-1}, 1163 \mathrm{~cm}^{-1}$, $1082 \mathrm{~cm}^{-1}$ were characteristic of acid C=0 stretching. Some peaks were recorded at $838 \mathrm{~cm}^{-1}, 799 \mathrm{~cm}^{-1}, 721 \mathrm{~cm}^{-1}$ due to the presence of aromatic C-H bending (Figure 3).

Hence, there was no major interactions between Aloe vera extract and excipients except some minor physical interaction which might be due to hydrogen bonding and vander wall forces and/or co-valent bonding [8].

Optical microscopic study showed that the oil globules were well dispersed throughout the external phase $(\mathrm{o} / \mathrm{w}$ emulsion). Absorption maxima occurred at $222 \mathrm{~nm}$, which indicated the presence of aloin in Aloe vera extract [10].

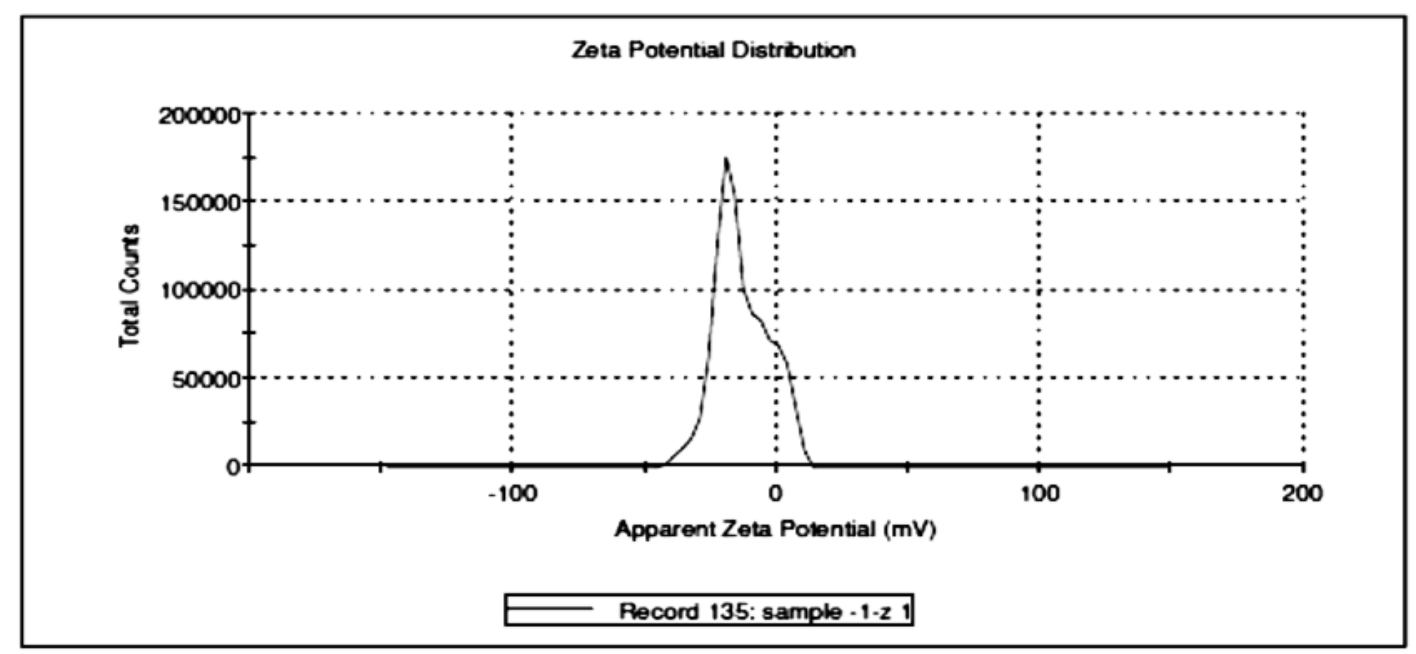

Figure 4 Zeta potential distribution of emulsion

Zeta potential of emulsion was observed to be $-13.2 \mathrm{mV}$ indicated the stability of emulsion with no agglomeration (Figure 4). Mean average particle size (oil globules) of emulsion was to be $481 \mathrm{~nm}$. Polydispersity index (PDI) was recorded to be 0.6 which explained the uniformity of oil globules (Figure 5) [12]. 


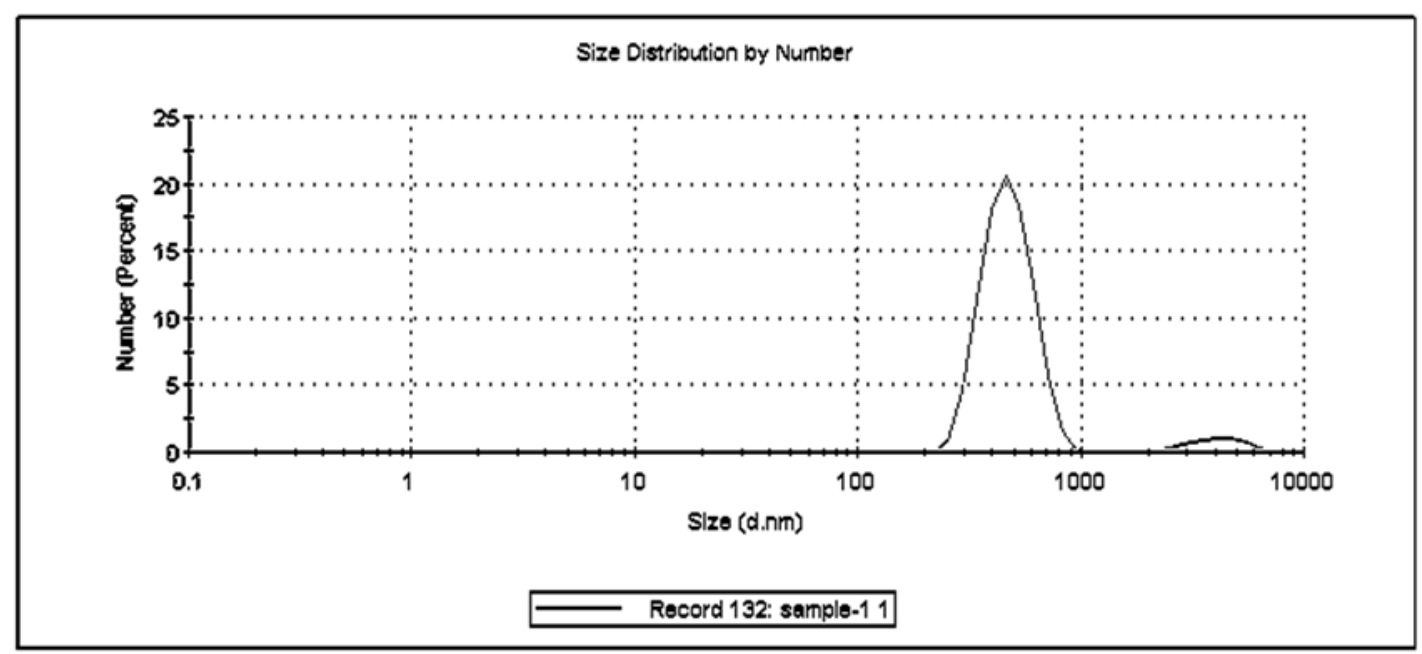

Figure 5 Particle size (oil globule size) distribution of emulsion

\section{Conclusion}

In conclusion, the emulsion was developed and emulgel was well formulated. The gel base was prepared by using carbomer 940 and Aloe vera extract. Zeta potential of emulsion indicated the stability of emulsion with no agglomeration. Average oil globule size $(481 \mathrm{~nm})$ of emulsion suggested that the preparation was nanoemulsion and polydispersity index (PDI) explained the uniformity of oil globules in nanoemulsion. Aloe vera extract was incorporated into emulgel with compatibility, no chemical interactions were reported. Viscosity and $\mathrm{p}^{\mathrm{H}}$ of formulated Aloe vera emulgel suggested which could be useful on skin application. Furthermore, extensive studies are required as dermal preparation of emulgel.

\section{Compliance with ethical standards}

\section{Acknowledgments}

The research work was supported by institutional research fund, Bengal School of Technology, Sugandha, Hooghly, West Bengal, India 712102.

\section{Disclosure of conflict of interest}

The researcher is in a supervisory relationship under corresponding author. The authors report no other conflicts.

\section{References}

[1] Mikari BV and Mahadik KR. (2010). Formulation and evaluation of topical liposomal gel for fluconazole. Indian J Pharm Science, 44(4), 324-325.

[2] Baibhav J. (2012). Development and characterization of clarithromycin emulgel for topical delivery. International Journal of Drug Development and Research, 4(3), 310-323.

[3] Liu P and Chen D. (2013). Chemical constituents, biological activity and agricultural cultivation of Aloe vera, Asian Journal of Chemistry, (12), 6477-6485.

[4] Cole L and Heard C. (2007). Skin permeation enhancement potential of Aloe vera and a proposed mechanism of action based upon size exclusion and pull effect. Int J Pharm, 333, 10-16.

[5] Forever Good Health, The Aloe Way, health care magazine, Forever Living Products; India, Pvt. Ltd. (2009). 3-22.

[6] Sierra-Garcia GD and Castro-Rios R. (2014). Acemannan, an extracted polysaccharide from Aloe vera: A Literature Riview. Natural Product Communications, 9(8), 1217-1221. 
[7] Das T, Manna M and Rudra A. (2020). Formulation and characterization of papaya leaf gel. GSC Biological and Pharmaceutical Sciences, (3), 89-94.

[8] Rudra A, Deepa RM, Ghosh MK, Ghosh S and Mukherjee B. (2010). Doxorubicin-loadeded phosphatidyl ethanolamine-conjugated nanoliposomes: in vitro characterization and their accumulation in liver, kidneys, and lungs in rats. International Journal of Nanomedicine, 5, 811-823.

[9] Sumathi A andSuriyaprakash TNK. (2016). Formulation and characterization of aloe emulgel using rice hulls as an excipient. Internation Journal of Research in Pharmacology \& Pharmaco therapeutics, 1, 24-31.

[10] Herbert AL, Martin MR andGilbert SB. (1988). Pharmaceutical emulsions, pharmaceutical dosage forms: Disperse System.Vol.1, Marcel Dekkar, New York and Basel.

[11] Megeressa M, Bisrat D and Mazumder A. (2015). Structural elucidation of some antimicrobial constituents from the leaf latex of Aloe trigonantha L.C. Leach. BMC Complementary and Alternative Medicine, 15:270

[12] Pecora R. (2000). Dynamic light scattering measurement of nanometer particles in liquids. Journal on Nanoparticle Research, 2(2), 123-131. 